\title{
Investigating the effect of connectivity of top management team on their resilience
}

\author{
Fariborz Rahimnia $^{\mathrm{a}^{*}}$, Shamsodin Nazemi ${ }^{\mathrm{b}}$ and Yashar Moradian ${ }^{\mathrm{c}}$
}

\begin{abstract}
${ }^{a}$ Associate Professor of Management, Faculty of Economic and Administrative Sciences, Ferdowsi University of Mashhad, Mashhad, Iran
${ }^{b}$ Professor of Management, Faculty of Economic and Administrative Sciences, Ferdowsi University of Mashhad, Mashhad, Iran 'Executive Master of Business Administration, International Campus, Ferdowsi University of Mashhad, Mashhad, Iran

C H R O N I C L E
\end{abstract}

Article history:

Received January 20, 2014

Accepted 5 July 2014

Available online

August 202014

Resilience

Top management team

Connectivity

Efficacious beliefs

Adaptive capacity

\section{Introduction}

Two recent decade's development in the fields of economic, social and culture has been changed the business environment, as these changes adding the dynamic and complexity of organizations environment, on the other hand, it has created different choices in order to provide value. In order that the organizations ensure their long-term survival in such circumstances and maintain their sustainable development and reliable performance in the future, it is important to develop capacity while enjoying the experience of past failures and have the ability to prepare themselves for the challenges and deal with them (Carmeli \& Markman, 2011; Carmeli \& Schaubroeck, 2006, 2008; Weick \& Sutcliffe, 2001). Moreover, organization and specially its top management team should be able to return from the situation called as the crisis to the situation that they can take maximum advantage of the potential opportunities in the crisis in addition to maintaining the survival of the organization. Such these capabilities are remembered as resilience in theoretical topics such as resilience

*Corresponding author.

E-mail addresses: r-nia@um.ac.ir (F. Rahimnia)

(c) 2014 Growing Science Ltd. All rights reserved doi: $10.5267 /$ j.ms 1.2014 .8 .025 
capabilities, so that the resilience is the capacity to respond positively and heal the failures (Bonanno, 2004; Fergus \& Zimmerman, 2005). Resilience is one of the newest topics that have attracted many areas of research, particularly the behavioral sciences, psychology, organization and management. Now, in order to apply and extend this research to a group level and consequently the management team as the team's strategic decisions, it is essential to do more studies to establish a deeper understanding of resilience at the group level. Since based on these studies, the organization's top management team is the most important factor influencing on the alignment of organization and environment and they can improve the adaptability to environmental conditions or lead an organization toward the failure of its objectives through the decisions that they took. Resilience topic could be the answer to this question why some of the top managers can easily cope and respond appropriately to these challenges in organizations with environmental challenges such as economic pressures, downturns, competitive pressures of demand and rapid technology changes (Carmeli et al., 2013). Like many studies accomplished on the processes within the team, the aim of the study of the organization's top management team is to explore the nature of these processes within the team. It also aims to explore its results achieved by examining the framework of the research related to the resilience and useful information about processes within the top management team. Understanding these processes within the team provides the background of awareness about the different strategic directions, improving the strategic choices and organizational performance by top managers (Barrick et al., 2007; Li \& Hambrick, 2005; Smith et al., 1994).

As a result, when the organization's top management team by creating processes within the proper and effective team cannot provide the background for improving the important decisions through forming a structured mechanism, they cannot use just the potential opportunities in terms of stability. However, when facing with environmental threats and challenges, they will fail responding and reacting appropriately to the crisis. In fact, evidences have been approved on this topic that the lack of attention of managers of industrial companies located in northeast of Iran, leads to their failure to adopt a comprehensive and strategic decision and finally results in negative consequences for them. Therefore, in this study the effect of the interaction of top management team on the level of resilience has been studied.

\section{Research Literature}

\subsection{Resilience}

Previous studies have defined resilience as the ability of individuals, groups and teams in order to absorb pressure, improve organizational performance when dealing with internal and external challenges, coincided with the revival of mishaps, failures and further prepare for various events (Sutcliffe \& Vogus, 2003). In this study, resilience will be examined from two dimensions: 1) Efficient belief to cope with the problems, challenges and the ability to solve them and 2) The versatility capacity with these challenges. Then, it will be referred to the beliefs that the team or organization has the capability to overcome various problems named as "resilience-efficacious beliefs" in this study. The word, efficacious, simply does not mean a true and real feature, but it returns to the extent of belief that members of a team have their abilities to perform certain tasks and certain matters in various conditions (Bandura, 1997). Sutcliffe and Vogus (2003) consider the efficacious of a team in perceptual-social beliefs in attracting challenges. Besides, resilience needs versatility capacity and positive adaptation in the face of problems (Carver, 1998; Masten \& Reed, 2002; Sutcliffe \& Vogus, 2003). Hereafter, resilience will be named as "resilience-adaptive capacity". Lengnick-Hall and Beck (2005) and Chakravarthy (1982) call the resilience-adaptive capacity as the sense capability, interpret and respond to internal and external complexity of those problems that turned into a working system and this system provides the alignment capability for obstacles and continuing growth path for the organization. Carmeli et al. (2013) refer to the relationship between resilience and integrity of strategic decisions like this way that the comprehensive process of strategic 
decisions allow the organization's top managers to understand better the conditions, resources and responding capabilities to opportunities and threats. For this reason, managers with high resiliency consider threats as challenges while managers with less resilience capabilities consider it as a threat. This feature will cause that the top managers get a deeper understanding of events, which could be regarded as a crisis and thereby they choose strategies appropriate to the circumstances. Interactions among individuals can have a great effect on a range of processes and especial behaviors (Kahn, $2001,2007 \mathrm{a}, 2007 \mathrm{~b}$ ), so that a positive interaction is effective among people on the quality of team work, which finally results in creating a flow of knowledge in line with the capacity for resilience (Carmeli et al., 2013).

\subsection{Connectivity}

In this study, interaction considered as relative mechanism that enables group members to understand the differences and learn disparate influences and diverse demands not in the form of threat but as an opportunity through which they can take full advantage of environmental opportunities, and walk-in the path of growth (Carmeli et al., 2013). Different connectivity with process structures of the top management team, including cohesion (Barrick et al., 2007) and behavioral integration (Hambrick, 1994). Cohesion and behavioral integration is attributed to connectivity and interactions among members where an interaction as a structural principle is concerned to the nature of the relationship between members (Carmeli et al., 2013). The study of Losada and Heaphy (2004) which is associated with evaluating a management of various sector teams Strategic Business Units (SBUs), on the connectivity strength is emphasized in explaining the causes of fluctuations in organizational performance. Their findings indicate that a high level of interaction between people is correlated with the level of organizational performance. In addition, the strength and frequency of the connectivity represents stable emotional, social and psychological atmosphere (Losada \& Heaphy, 2004). In this regard, Fredrickson (2001) states that this theory when people experience positive emotions expanded their scope of thoughts and activities also will generate resources that enabling them to effectively manage such events, while others are incapable of doing it. Similarly, such a situation happens when the positive attitudes prevent the organization to impact from unpleasant events. This is by fostering resilience and also it is accomplished through tendency toward positive attitudes that such approaches seems to be necessary for the collective survival (Cameron et al., 2011). Besides, such a thing will help teams process information completely, thoroughly review emergency and critical conditions, and developed operational plant use the opportunities, in other words, to achieve a comprehensive decision and finally to provide the ability to learn from the past failures and the compensation. In addition to the results of the study of Carmeli et al. (2013) stating that connectivity with top managers lead to greater participation in their comprehensive strategic decisions, Sutcliffe and Vogus (2003) have shown that extensive processing of information to build resilience capacity seems vital.

\subsection{Conceptual Model}

With the assistance of the literature, the subject and the background of research presented conceptual model associated with examining the impact of connectivity of the top management team in organization on their resilience capacity. In presenting this model, the research topics related to the connectivity of the top management team of organization taken from the studies of Dutton (2003), Dutton and Heaphy (2003) and Ragins and Dutton (2007); in order to better understand this concept, which communication procedure impact on cognitive processes and how managers capabilities. Although few studies have been accomplished on the connectivity of the top management team, but Losada and Heaphy (2004), studied the connectivity of top management team in 60 business units and recognize edits direct impact on long-term and short-term decisions. These studies show that high levels of communication between top managers in organization will expand their management knowledge. Previous studies in this are very limited and only Sutcliffe and Vogus (2003) attempted to directly evaluate their resilience of top management team. In addition, for the first time Carmeli et al. 
(2013) studied two dimensions of resilience through gathering literature about the resilience, processes of top management team, high quality connectivity and decision-making processes. Although studies of Powley (2009), Sutcliffe and Vogus (2003) provided theoretical principles and the required literature on the power of communication mechanisms to foster resilience in the organization. Thus, according to previous research and literature relevant to this research, conceptual model and the following hypotheses that adapted from the investigation model of Carmeli et al. (2013) intended to do this research.

Hypothesis 1: connectivity of top management team affects the efficacious beliefs of resilience. Hypothesis 2: connectivity of top management team affects the adaptive capacity of resilience.

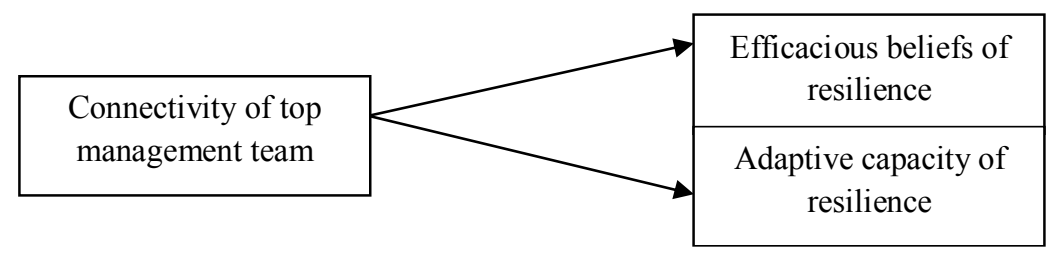

Fig. 1. Conceptual model of research (Adapted from Carmeli et al., 2013)

\section{Method}

This study is applied in terms of goal and survey/analytical in terms of data gathering method, which utilizes the structural equation modeling. The statistical population of this study is the top management teams of 500 firms located in North-East of Iran. These managers were the most informed people to answer the questionnaires given their key role in making strategic decisions. It should be mentioned that the top management team comprises the executive managers and those people who participate in the process of decision-making if the CEO permits (Hambrick \& Mason, 1984). The simplified random sampling was conducted to select the participants and distribute the questionnaires. Furthermore, the Cochran's formula with the confidence level of .95 determined the sample size of 117 firms (standard deviation of statistical population was estimated .627 by conducting a pre-test of 30 participants) and 139 questionnaires were returned. Research constructs were the connectivity of top management team and dimensions of their resilience.

To measure the efficacious beliefs of resilience, 3 items of Chen et al. (2001) were used. A sample item is: "When the top management team encountering a new and difficult task, it is certain it can do it successfully". To measure the adaptive capacity of resilience, we used 3 items from the questionnaires of Carmeli et al. (2010); Carmeli and Sheaffer (2008). A sample item is: "To which extent, the top management team makes the necessary changes and adoptions to respond effectively to changes in the industry". To measure the variable of connectivity of top management team, 6 items of Carmeli and Spreitzer (2009) were used. A sample size is: "To which extent the relationship between top management team is open". It should be noted that all the items were measured with a 5point Likert scale ranging from "very low" to "very high". To ensure from the participation of respondents, the content and construct validity of questionnaire was investigated using pre-test. The content validity was evaluated using the experts' opinions and construct validity was evaluated using confirmatory factor analysis. The questionnaire's reliability was also evaluated using Cronbach's alpha coefficient, which is the most common test for internal consistency of multifactor scales. And finally, research data was analyzed by conducting structural equation modeling in Amos software.

\section{Findings}

\subsection{Descriptive statistics}

Among the respondents, $67.6 \%$ were male, $69.1 \%$ were married, and subject's ages ranged from 24 to 58 , with an average age of about 30 years. $1.2 \%$ of the respondents reported that the highest level of 
education that they had completed was diploma or lower, $60.4 \%$ bachelor degree, $30.2 \%$ reported obtaining a master degree, 5\% doctorate degree, and the rest was unknown. The means, standard deviations, correlations, and internal consistency among study variables are provided in Table 1. As can be seen, the correlation between all variables is significant and the alpha coefficients are greater than .80 .

\section{Table 1}

Means, standard deviations, correlations, and internal consistencies

\begin{tabular}{lccccc}
\hline Variables & Mean & SD & 1 & 2 & 3 \\
\hline 1. Connectivity of top management team & 3.56 & .71 & $(.87)$ & & \\
2. Efficacious Beliefs of Resilience & 3.70 & .64 & $.55^{* *}$ & $(.83)$ \\
3. Adaptive capacity of resilience & 3.57 & .74 & $.59^{* *}$ & $.67^{* * *}$ & $(.81)$ \\
\hline $\mathrm{p}<.01$ & & & & &
\end{tabular}

\subsection{Hypotheses testing}

Before running SEM model, we conducted a CFA to see if each item is statistically significant loaded to its relevant construct. The measurement models were assessed using fit indices and the regression weights significance. Based on the results of the CFA model, all items were significant which detailed results are shown in Table 2. It should be noted that the items are significant if their p-value for factor loadings is less than .05 [CFA indices: $\chi^{2}{ }_{(51)}=76.38 ; \chi^{2} / \mathrm{df}=1.498 ; \mathrm{NFI}=.91 ; \mathrm{CFI}=.97$; $\mathrm{GFI}=.91 ; \mathrm{RMR}=.033 ; \mathrm{RMSEA}=.060]$. Fit indices indicates that the CFA model is goodly fitted to data.

Table 2

Results of confirmatory factor analysis for construct validity

\begin{tabular}{|c|c|c|c|c|c|c|c|}
\hline \multirow{3}{*}{$\begin{array}{l}\text { Connectivity of top } \\
\text { management team }\end{array}$} & Item & 1 & 2 & 3 & 4 & 5 & 6 \\
\hline & FL & .67 & .73 & .70 & .86 & .77 & .71 \\
\hline & $\mathrm{p}$-value & .000 & .000 & .000 & .000 & .000 & .000 \\
\hline \multirow{3}{*}{$\begin{array}{l}\text { Efficacious Beliefs of } \\
\text { Resilience }\end{array}$} & Item & 12 & 13 & 14 & & & \\
\hline & FL & .73 & .84 & .82 & & & \\
\hline & $\mathrm{p}$-value & .000 & .000 & .000 & & & \\
\hline \multirow{3}{*}{$\begin{array}{l}\text { Adaptive capacity of } \\
\text { resilience }\end{array}$} & Item & 15 & 16 & 17 & & & \\
\hline & FL & .68 & .82 & .83 & & & \\
\hline & $\mathrm{p}$-value & .000 & .000 & .000 & & & \\
\hline
\end{tabular}

After evaluating the construct validity, the structural model was run which can be seen in Fig. 2. Hypotheses were tested based on the coefficients of the fitted SEM model $\left[\chi_{(50)}^{2}=90.32 ; \chi^{2} / \mathrm{df}=\right.$ $1.80 ; \mathrm{NFI}=.90 ; \mathrm{CFI}=.95 ; \mathrm{GFI}=.90 ; \mathrm{RMR}=.048 ; \mathrm{RMSEA}=.076]$. Each hypothesis is confirmed if its related $p$-value is less than .05 .

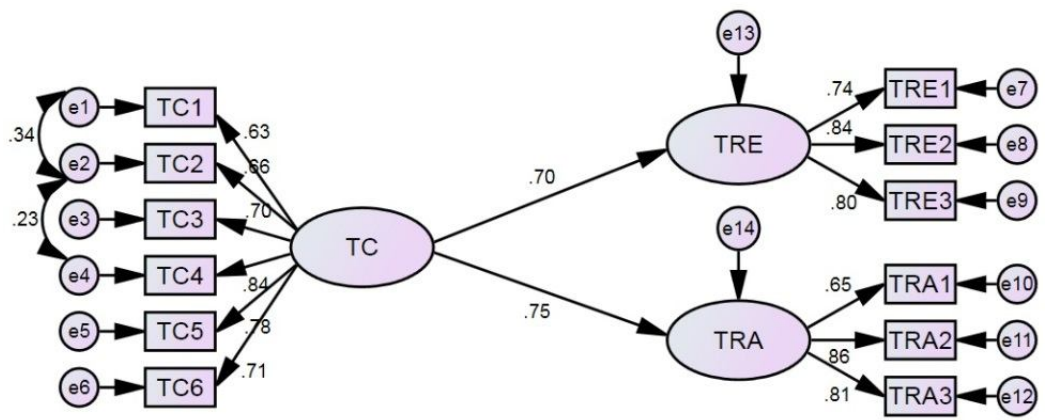

Fig. 2. Research structural model

Research hypotheses postulated that the connectivity of top management team affects the efficacious beliefs of resilience $(\beta=.70, \mathrm{sig}=.000)$ and adaptive capacity of resilience $(\beta=.75$, sig $=.000)$. As results showed, these two hypotheses were statistically confirmed. Detailed results of hypotheses testing are shown in Table 3. 
Table 3

Results of hypotheses testing

\begin{tabular}{ccccc}
\hline hypothesis & Relationship & Beta & sig & result \\
\hline 1 & TC/TRE & .70 & .000 & accepted \\
2 & TC/TRA & .75 & .000 & accepted \\
\hline
\end{tabular}

\section{Discussion}

In general, the results of this study confirmed all hypotheses of the conceptual model. In other words, the findings of this study indicated that: 1) Connectivity of top management team is associated positively with resilience-efficacious beliefs, 2) Connectivity of top management team is associated positively with the resilience-adaptive capacity. This paper examined the importance of senior managers' connectivity in organizations so that it could be a basis for their resilience. The results of this study are consistent with the previous studies such as Woods and Branlat $(2010,2011)$, Powely (2009), Sutcliffe and Vogus (2003), Carmeli et al. (2013) in the field of effect of interactive mechanisms on resilience and also coping with the challenges and problems.

In this paper, firstly the processes within the top management team were studied through the past studies such as Dutton (2003), Dutton and Heaphy (2003) and Ragins and Dutton (2007) in the field of high quality connections, and towards the deeper and more understanding of its effect on cognitive processes and capabilities of the top management team. Therefore, the findings indicate that a high level of connectivity of top management team facilitates developing knowledge of top management team (Hambrick \& Finkelstein, 1987). Mechanisms of interaction between top management lead to creation of an environment in which the managers will be able to talk freely with each other and obtain the information needed to make strategic decisions efficiently.

Although the results of this study enriches the debate and the issues related to the impact of strategic decisions on the quality of decisions made and performance of the organization, but the effective engagement of the top management team on organizational resilience seems very important. As mentioned in the theoretical framework of the study, the studies of organizational resilience are very limited; here the study of Sutcliffe and Vogus (2003) can be pointed out, although the resilience of top managers has been less examined in this study. This study also approved the results of the study by Wreathall (2006) that the resilience needed to collect a range of information, not only about the output, but also information about the central and peripheral activities that cause adaptability to the environmental challenges.

According to the material presented, we can conclude that many organizations especially top organizations and their top management team provide an optimum use of opportunities facing the adversity while believing in their abilities and beliefs in order to solve problems with effective use of resources in order to cope better with the challenges. However, future studies should consider the fact that the changes of structure and top management team members can contribute by increasing their resilience that should be further studied. The theoretical framework is about how to form a team in order to create and improve processes within the top management team by managing resiliency, rare and merits further study. Judging the level of strategic decisions in organizations, countries and industries is different and consequently the determination of the type of challenge and resilience of top management team in facing with these problems can also be considered as a basis for future research. According to findings, practical suggestions for managers of north-east of Iran are provided as follows:

Since the connectivity of top managers in the organization can also create an intimate atmosphere resulting in the current flow of information and knowledge amongst them, the CEO and top management team should be given more attention than the development of an interactive space and 
this could affect the style and quality of strategic decisions and minimize the knowledge defects in this team at decision making time. In addition, to improve the quality of strategic decisions of top management team under normal circumstances when an organization faces a major challenge such as exchange rate changes, sudden market downturn, especially in the face of sanctions, top management team that has a positive attitude towards its ability and could create the necessary adaptability with environmental changes such as diversification of products, changes in strategy, marketing and sales, service development, or even provide alternatives imports of raw materials is surely more successful than organizations that merely rely on a strategy for their survival. It is suggested that the top managers in organizations adopt such an approach smooth the direction of the organization in achieving its strategic objectives in today's competitive and complex businesses. This research title could be examined in other governmental and non-governmental agencies; thereby a more complete understanding than the managers' resilience against various issues could be achieved. It can also help top managers to be aware of the significance of this issue to understand the connectivity mechanisms, discussions, interactions, efficient decision-making processes, improving resiliency and consequently create a sustainable competitive advantage for organizations at the national and international arena.

\section{References}

Bandura, A. (1997). Self-efficacy: The Exercise of Control. W.H. Freeman, New York.

Barrick, M. R., Bradley, B.H., \& Colbert, A.E. (2007). The moderating role of top management team interdependence. Implication for real teams and working groups. Academy of Management Journal, 50, 544-557.

Bonanno, G. A. (2004). Loss, trauma, and human resilience: have we underestimated the human capacity to thrive after extremely aversive events?. American Psychologist, 59, 20-28.

Cameron, K., Mora, C., Leutscher, T., \& Calarco, M. (2011). Effect of positive practices on organizational effectiveness. Journal of Applied Behavioral Science, 47, 266-308.

Carmeli, A., Friedman, Y., \& Tishler, A. (2013). Cultivating a resilience top management team: The importance of relational connections and strategic decision comprehensiveness. Safety Science, 51, 148-159.

Carmeli, A., Gelbard, R., \& Gefen, D. (2010). The importance of innovation leadership in cultivating strategic fit and enhancing firm performance. The Leadership Quarterly, 21, 339-349.

Carmeli, A., \& Markman, G.D. (2011). Capture, governance, and resilience. Strategy implications from the history of Rome. Strategic Management Journal, 32, 322-341.

Carmeli, A., \& Schaubroeck, J. (2006). Top management team behavioral integration decision quality, and organizational decline. The Leadership Quarterly, 17, 441-453.

Carmeli, A., \& Schaubroeck, J. (2008). Organizational crisis-preparedness: The importance of learning from failures. Long Range Planning, 41, 177-196.

Carmeli, A., \& Sheaffer, Z. (2008). How learning leadership and organizational learning from failures enhance perceived organizational capacity to adapt to the task environment. Journal of Applied Behavioral Science, 44, 468-89.

Carmeli, A., \& Spreitzer, G.M., (2009). Trust, connectivity and thriving: implications for innovative behaviors at work. Journal of Creative Behavior, 43, 169-191.

Carver, C.S. (1998). Resilience and thriving: Issues, models, and linkages. Journal of Social Issues, 45, 245-266.

Chakravarthy, B. S. (1982). Adaptation: a promising metaphor for strategic management. Academy of Management Review, 7, 35-44.

Chen, G., Gully, S.M., \& Eden, D. (2001). Validation of a new general self-efficacy scale. Organizational Research Methods, 4, 62-83.

Dutton, J. E. (2003). Energize your work place. How to build and sustain high-quality connections at work. Jossey-Bass Publishers, San Francisco.

Dutton, J. E., \& Heaphy, E.D., (2003). The power of high-quality connections at work. Positive Organizational Scholarship, 263-278 
Fergus, S., \& Zimmerman, M.A. (2005). Adolescent resilience: a framework for understanding healthy development in the face of risk. Annual Review Public Health, 26, 399-419.

Fredrickson, B. L. (2001). The role of positive emotions in positive psychology: The broaden and built theory of positive emotions. American Psychologist, 56, 218-226.

Hambrick, D. C. (1994).Top management team groups: A conceptual integration and reconsideration of the "team" label. Research in Organizational Behavior, 171-214.

Hambrick, D., \& Finkelstein, S. (1987). Managerial discretion: a bridge between polar views on organizations. Research in Organizational Behavior, 9, 369-406.

Hambrick, D. C., \& Mason, P.A., (1984). Upper echelons theory: the organization as a reflection of its top management. Academy of Management Review, 9, 193-206

Kahn, W. A. (2001). Holding environment at work. Journal of Applied behavioral Science, 37, 260279.

Kahn, W. A. (2007a). Commentary: positive relationship in groups and communities. Lawrence Erlbaum Associates, Mahwah, NJ, 189-207.

Kahn, W. A. (2007b). Meaningful connections: positive relationships and attachments at work. Lawrence Erlbaum Associates, Mahwah, NJ, 189-207.

Lengnick-Hall, C. A., \& Beck, T.E. (2005). Adaptive fit versus robust transformation: how organizations respond to environmental change. Journal of Management. 31(5), 738-757.

Li, J. T., \& Hambrick, D.C. (2005). Factional group: a new vantage on demographic faultiness, conflict, and disintegration in work teams. Academy of Management Journal, 48, 794-813.

Losada, M., \& Heaphy, E. (2004). The role of positivity and connectivity in the performance of business teams: a nonlinear dynamics model. American Behavioral Scientist, 47, 740-765.

Masten, A. S., \& Reed, M.J. (2002). Resilience in development. In: Snyder. Handbook of Positive Psychology. Oxford University Press, New York, 74-88.

Powley, E. H. (2009). Reclaiming resilience and safety: resilience activation in the critical period of crisis. Human Relations, 62, 1289-1326.

Ragins, B. R., \& Dutton, J.E. (2007). Positive relations at work: an introduction and invitation. Lawrence Erlbaum Associates, Mahwah, NJ, 1-25.

Smith, K. G., Smith, K.A, Olian, J.D., Sims, H.P., O'Bannon, D.P., \& Scully, J.A. (1994). Top management team demography and process: the role of social integration and communication. Administrative Science Quarterly, 39, 94-121.

Sutcliffe, K. M., \& Vogus, T.J. (2003). Positive Organizational Scholarship: foundations of a new discipline. Barrett-Koehler, San Francisco, 94-121.

Weick, K. E., \& Sutcliffe, K.M. (2001). Managing the unexpected: Assuring high performance in the age of complexity.

Woods, D. D., \& Branlat, M. (2010).Hollnagel's test: being ' in control of ' highly interdependent multi-layered networked systems. Cognition, Technology \& Work, 12, 95-101.

Woods, D. D., \& Branlat, M. (2011). Basic patterns in how adaptive systems fail. Resilience engineering in practice. Ashgate, Farnham, UK, 127-144.

Wreathall, J. (2006). Properties of resilient organizations: an initial view. Resilience engineering: Concepts and Percepts. Ashgate, Farnham, UK, 275-285. 